\title{
EL ROL DEL LENGUAJE EN LA OFERTA TURÍSTICA: GASTRONOMÍA Y ONOMÁSTICA DE RESTAURANTES EN PLAYA JACÓ ( PACÍFICO CENTRAL DE COSTA RICA)
}

\author{
The role of language in the turist offer: gastronomy and onomastics \\ in restaurants in Jaco Beach (Central Pacific of Costa Rica)
}

\section{Giselle Chang Vargas*}

\begin{abstract}
RESUMEN
En este artículo presentamos la relación que existe entre el turismo y el tipo de lenguaje utilizado en una oferta determinada, en este caso, la gastronómica. El lugar de estudio es Playa Jacó, conocido centro turístico del Pacífico costarricense. La información se registró mediante trabajo de campo y se analizó con un enfoque interdisciplinario (lexicografía y antropología lingüística).. Se presentan varias clasificaciones del léxico según la lengua del nombre de los restaurantes, refresquerías y afines; la lengua del menú; la procedencia de las comidas, para estimar el nexo con el patrimonio local.

Palabras clave: lenguaje, turismo, gastronomía, onomástica, identidad cultural
\end{abstract}

\begin{abstract}
In this paper we present the relationship between tourism and a type of language used in a particular offer: the gastronomy. The study was carry out in Jacó Beach, a touristic center in the Costa Rican central pacific coast. The information was recorded through field work and analyzed with an interdisciplinary focus (lexicography and linguistic anthropology. We present several lexical classifications about the language of the restaurants' names, juice bars and related, the menu language, the origin of the food, to estimate the link with the local cultural heritage.
\end{abstract}

Key Words: language, tourism, gastronomy, cultural identity

Universidad de Costa Rica. Catedrática de la Escuela de Antropología. Costa Rica.

Correo electrónico: tunichang@gmail.com

Recepción: 9/6/2013 Aceptación: 15/11/2013. 


\section{Introducción}

Las formas de comunicación que nos permite el lenguaje son inmensas, pues tanto en el plano de lo verbal como de lo verbal, hay una variedad de signos, que nos abren un espectro casi ilimitado. Son innumerables los fenómenos culturales y naturales, así como la multiplicidad de temas y enfoques para incrementar el conocimiento de lo humano.

El turismo nos abre un abanico de posibilidades para conocer más los patrones discursivos de una sociedad, tomando como centro el lenguaje. En este trabajo nos enfocaremos en un caso particular: la oferta turística vista desde el léxico de la gastronomía y la onomástica de restaurantes y establecimientos afines.

El turismo es un fenómeno polifacético, complejo y a veces contradictorio. Es una actividad económica y cultural, una empresa o industria cultural, por lo que sus intereses no son homogéneos. Toda actividad turística tiene distintos componentes básicos, pues según los diversos estudios, algunos le dan más atención a la demanda de servicios, a la distribución y ventas, al marketing, al comportamiento del consumidor, etc. El antropólogo Peter Burns (2002:43), considera que si hay consenso en reconocer cuatro elementos básicos: la demanda por los viajes, los intermediarios del turismo, las influencias ligadas al destino y la gama de impactos.

En la jerga turística el lugar donde se viaja se conoce comúnmente como destino. Hay lugares destino que ofrecen más atractivos desde el punto de vista de conocer la diversidad lingüística y en el caso de los sitios de turismo masivo, es frecuente el uso de al menos dos lenguas: el español, como oficial del país, con sus variedades regionales y el inglés, como lengua de comunicación comercial internacional. Para este estudio se escogió la Región del Pacífico Central de Costa Rica pues es una de las regiones de más desarrollo de turismo masivo del país.

El objetivo final del trabajo era estimar la relación ente la oferta turística en materia gastronómica y la identidad cultural local.
Para lograrlo, nos propusimos otros objetivos específicos como:

1) Clasificar la oferta gastronómica según la lengua o lenguas en que está escrito el nombre del lugar; la lengua o lenguas en que está escrito el nombre de las comidas y bebidas $\mathrm{y}$, el lugar de origen de las comidas y bebidas.

2) Clasificar semánticamente los nombres de restaurantes, con el fin de estimar la relación con las características del contexto natural y socio-cultural de la región y específicamente de Jacó.

3) Identificar el lenguaje del turismo, cifrado en las frases más comunes utilizadas en folletos publicitarios locales.

El artículo se divide en tres secciones: un bosquejo sobre el lenguaje del turismo; una reseña de las imágenes que proyecta la oferta turística sobre la región del Pacífico Central; la metodología de la investigación; el desarrollo de los resultados sobre los objetivos propuestos y, unas consideraciones finales.

\section{Lenguaje y Turismo}

\subsection{Lenguaje del turismo}

El turismo es una industria cultural y una actividad económica emblemática de nuestra era. La promoción turística se vale de diversos de comunicación: la radio, la televisión, la prensa, internet, la transmisión de boca en boca y las redes sociales.

El estudio sobre el lenguaje del turismo ha sido desarrollado por Graham Dann (1993) y por un grupo de investigadores de universidades italianas, entre ellos M.V. Calvi, G. Mapelli y L.J. Santos en Milano; M. Franch, O. Pallusci en Trento (cfr. http: //polaris. Unitn.it).

Al tratar el lenguaje del turismo nos encontramos se perfila desde diferentes campos de estudio, lo que dificulta precisar con claridad sus fronteras. 
Sin embargo, desde otra perspectiva, esto es un atributo del lenguaje del turismo es que "habla con una lengua multidisciplinaria", pues la oferta turística se fundamenta en temas ecológicos, arquitectónicos, arqueológicos, etnológicos, artísticos, religiosos y gastronómicos, entre los principales. En este trabajo nos enfocaremos en este último tema.

El lenguaje del turismo (LT) ha sido considerado como un caso de lengua especial, pues ha tenido la capacidad de generar nuevos términos, como tour operator, package holidays, acuñados en inglés y utilizados internacionalmente. Desde este punto de vista podríamos suponer que el turismo ha contribuido a la comunicación entre viajeros que no tienen ninguna lengua en común. Esta semejanza con la lingua franca, es más evidente en los grandes aeropuertos internacionales, donde se oyen ciertas palabras y frases, que forman parte de un vocabulario del turismo, comprensible por una diversidad de hablantes.

Otra manera de concebir la función del lenguaje del turismo, es caracterizarlo como una forma de control social, para lo que se vale de varias estrategias tanto lingüísticas (el uso de metáforas, hipérbole, metonimia, adjetivos calificativos, símil, etc.,), como extralingüísticas (actitudes, creencias, estereotipos, valores socioculturales, de un grupo determinado.

Roman Jacobson reconoce varias funciones en el lenguaje, que no se presentan por igual en todos los géneros discursivos $\mathrm{y}$, en lo específico al turismo, observamos en este un predominio de las funciones informativa, argumentativa y persuasiva. La oferta debe enunciar cuáles son los atractivos de un lugar; pero, requiere de justificaciones que prueben sus particularidades, para terminar con frases elocuentes que conduzcan a un individuo a ir a un determinado sitio, donde realizará sus deseos. Consideramos que debemos agregara la función situacional o contextual, postulada en la etnografía del habla por John Gumperz y Dell Hymes (1992, pues ella nos refiere a la situación que rodea a la comunicación. En el caso que nos ocupa, ya se logró que un individuo viajara a Jacó, pero, ahora, es importante sugerirle qué debe hacer allí. Como mencionamos al inicio de este trabajo, hay que indicarle dónde puede ir a desayunar, tomar una merienda o algo refrescante, almorzar, cenar. Una sola imagen visual de la calle principal de Jacó, nos trae a la mente una serie de rótulos y otros textos llamativos que nos invitan a comer o beber.

Ya sea que el turista organice independientemente su viaje o que recurra a los servicios de una agencia, la oferta gastronómica está para satisfacer la diversidad de visitantes: individuales, en grupos pequeños o grandes, en espacios abiertos o cerrados, con diferentes opciones de precios y menús. El uso del lenguaje para comunicar estos mensajes es un eje transversal de la actividad turística.

\subsection{La relación gastronomía y turismo}

Hay algo muy cierto, en que coinciden todos los actores sociales que participan en la dinámica de la actividad turística, es decir, las personas o comunidades receptoras de turistas, los intermediarios (operadores y guías, empresas de transporte, alojamiento, alimentación, etc.) y, los viajeros turistas que visitan un lugar: a cualquier lugar que se visite es necesario comer y beber.

Al regreso de un viaje podemos no haber realizado varias actividades como: visitado ruinas o plazas, observado aves en el bosque nuboso o ballenas en el mar, haber visto espectáculos de rituales dancísticos, asistido a algún concierto, ido a bailar, ni subido montañas o haber descansado en la playa ...pero, nunca se viaja sin haber comido, aunque sea un bocadillo.

Comer es una necesidad primaria de los seres vivos, pero la manera en que se realiza ese acto es un hecho cultural. El proceso de alimentarse desde la búsqueda de los ingredientes, la conservación de los alimentos, el tipo de utensilios o tecnologías con que se preparan, la clase de estilos de preparación (hervido, asado, frito, sancochado, ahumado, etc.) tiene sus usos particulares en las distintas culturas. 
El tema de las comidas y bebidas es parte del campo semántico de la gastronomía, que según el Diccionario de la Real Academia Española (DRAE, 2001, 1124) es una palabra que procede del griego: $\gamma \alpha \sigma \tau \rho o v o \mu i ́ \alpha$ y, tiene estas dos acepciones: arte de preparar una buena comida y afición a comer regaladamente. Preferimos la primera, pues nos remite a la relación cultura-comida, pues la concepción de arte no se aplica a toda actividad humana y, lo que se considera buen comer, es algo relativo a cada cultura. Para muchos pueblos, el cerdo o la res son carnes muy apetecidas, mientras que para los judíos y los hindúes, respectivamente, son alimentos prohibidos por motivos religiosos.

La cocina y lo que servimos en la mesa son una forma de intercambio y de comunicación, donde además de los alimentos, intervienen elementos intangibles que se dan en las formas de comensalismo. El campo de la gastronomía es un espacio para fortalecer el patrimonio cultural de un pueblo, pues los seres humanos de una sociedad han creado productos que además de satisfacer el hambre y el gusto, denotan costumbres y saberes tradicionales de un lugar.

En Costa Rica podemos distinguir distintas tradiciones culinarias, que son el fruto de la diversidad cultural en nuestras herencias y así en unos lugares más que en otros, se verá la huella indígena, africana, europea o asiática (Chang, 2002). A grandes rasgos reconocemos la cocina guanacasteca, basada en el uso del maíz; la del Valle Central, con sus picadillos; la caribeña, con los tubérculos y el aceite de coco; la de las costas y montes, con la preparación de platillos a base de pescado y carnes. En el legado culinario costarricense hay técnicas y productos indígenas (por ejemplo, sancochar pejibayes, moler maíz y asar tortillas, picar tomate, etc.); europeos (por ejemplo, hornear pan, batir crema dulce para un mousse); asiáticas (por ejemplo, el uso del curry y el jengibre, los fideos con verduras y carnes, etc.).

El dinamismo y nuevos contactos interculturales propician cambios en las cocinas nacionales y regionales, pero sin perder la herencia. Concordamos con las palabras de Marjorie Ross (2001: 31):

\begin{abstract}
En todo el mundo se está dando una revaloración de las cocinas nacionales, rejuvenecidas con las ventajas de la vida moderna, pero sin despreciar las valiosísimas experiencias que han sido pasada de generación en generación. También nosotros nos hemos visto obligados, por el auge del turismo a repensar lo propio, a desempolvar las recetas de las abuelas y a buscar sus raíces, para comprendernos mejor a nosotros mismos y para ofrecer al visitante un menú original.
\end{abstract}

Consideramos que la gastronomía se opone a la "macdonalización" y otras formas de vender alimentos, preparados en serie, donde hasta las papas (originarias del sur de América), son importadas, ya peladas, pre-cocinadas y congeladas, listas para freír....No es tema de este artículo la preocupación por lo nutritivo, por eso no seguimos con el comentario acerca de las transnacionales de comidas rápidas. No obstante, si cabe sostener que estas empresas son lo opuesto a la gastronomía, pues no apelan a las tradiciones culinarias y pretenden cubrir esta ausencia con la apropiación de alimentos locales (por ejemplo, el bk pinto, la pizza con loroco ${ }^{1}$.

Las personas que tienen la oportunidad de aprovechar su tiempo libre en la visita de otros lugares, tienen un común denominador que es la búsqueda de nuevas experiencias, ya sea mirando el paisaje natural o alguna construcción humana, sea un edifico de valor histórico-arquitectónico o un espectáculo musical o dancístico. El desarrollo del turismo se ha enfocado en la vista, pero cada día es más frecuente una demanda diferente, en que se usen otros sentidos y se participe del entorno.

La industria turística debe estar al tanto de las necesidades del mercado y de ahí la incursión en nuevos campos y destinos, la diversificación en sus componentes con el propósito de satisfacer una tipología más amplia y por supuesto, lograra su fin, de mayor competitividad y rentabilidad. En este contexto, la gastronomía se ha convertido en un elemento importante para la nueva oferta, que ha generado una serie de términos para establecer la relación que existe entre cocina y turismo, como señalan López Guzmán 
y Sánchez Cañigua, 2012:571), entre ellos: cuisine tourism, gourmet tourism, food tourism, culinary tourism, gastronomic tourism.

En la oferta gastronómica en ciudades y poblados ubicados en la costa, se espera que haya una tradición de platillos basados en productos marinos, propios de la zona, con el agregado de la sabiduría en la relación del ser humano con el mar, cifrado en los conocimientos de pesca, técnicas de elaboración del platillo, entre una serie de actividades involucradas en el proceso alimentario.

\subsection{El turismo en el Pacífico Central}

Desde la década de los 80 el turismo se ha ido empoderando de la economía nacional y ya para fines del siglo XX, era cosa del pasado la imagen de Costa Rica, como el país de campesinos, sabaneros y pescadores. Tras siglos de tener un sistema económico basado en el sector agropecuario, con diferentes modelos de desarrollo desde sustituir los productos tradicionales por novedosas especies; la sustitución de importaciones y el desarrollo industrial, fue la actividad turística, la que se consolidó y desarrolló, por lo que ha pasado a ser la base de ingresos del país. El ICT divide el país en siete regiones turísticas: Valle Central, Llanuras del Norte, Puntarenas, Islas del Golfo y Monteverde, Guanacaste, Pacífico Central, Pacífico Sur y Región Caribe.

En este artículo nuestro destino de interés es Jacó, se ubica en el Pacífico Central. El poblado de Jacó se localiza en el distrito homónimo, en el cantón de Garabito, provincia de Puntarenas. Según un estudio demográfico del Centro Centroamericano de Población (Rosero Bixby, 2002) la estimación en el Distrito de Jacó pasó de 2.330 habitantes en 1970 a 15.933 en el año 2010. La fuente de ingresos de la gran mayoría de la población es el turismo, que aparecen en actividades de servicios intermediarios como la venta de alimentos, restaurantes, hotelería, transporte, lavandería, diversión, etc.

En el Mapa de la Zona Turístico del Pacífico Central (ICT, 2009), se señala a Jacó como una de las dos ciudades, además de Quepos con mayores atractivos y desarrollo turísticos, entre ellos: la biodiversidad de las playas y colinas cercanas a la costa, los atractivos de carácter cultural y recreativo.

\section{MAPA 1.}

Pacífico Central de Costa Rica. Fuente: http://www. govisitcostarica.co.cr/region/area.asp?AID $=9$

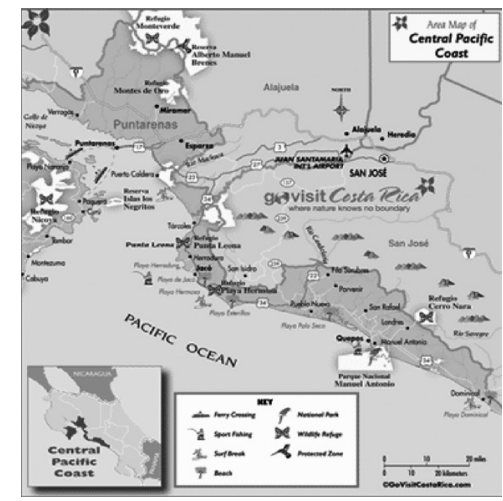

Aunque todavía muchos turistas que visitan la región del Pacífico Central, se conocen (en la jerga turística), como buscadores de la triple "s", es decir de sun, sea, sand/sol, mar y arena, la oferta se ha diversificado, tanto en el tipo de turistas y en la oferta.

Las nuevas formas de comunicación y organización
económica ......., lo ha hecho mucho más fácil (y
por lo tanto más barato) de organizar programas
adaptados a los intereses diferenciados de cada
grupo pequeño de turistas (y ofrecer programas
variados, desde excursiones para los 'turistas de
masa', pasando por las ofertas para los 'turistas
de mochila' hasta programas de 'turismo de lujo.
exquisito') (Hein, 2001-2002:41).

Lo señalado en la cita anterior por Wolfgang Hein, en el marco del desarrollo del turismo en la globalización, se aplica al caso de Jacó, donde el atractivo del sol y la playa, se agregan los campeonatos de surf, las caminatas por senderos de los bosques cercanos, la observación de la flora y la fauna, la pesca deportiva y el golf, el cannopy, las caminatas o recorridos a caballo por senderos boscosos, 
entre otras de las nuevas actividades. No se menciona el turismo sexual, pero, esa es una actividad que atrae a muchas personas, como lo observamos en una de las visitas y como lo manifestaron algunos habitantes del lugar.

Hay varios idearios o construcciones temporales del turismo que se observan en Jacó: el deseo de evasión, que como señala Daniel Hiernaux (2002:20), para algunos sigue siendo la utopía o el sueño imposible, que algunos logran, por "la intervención de agentes económicos astutos, los 'mercaderes de la felicidad', para incluir en el acto turístico dentro de paquetes de servicios comercializables a bajo costo". Otro ideario es el regreso a la naturaleza, aunque para esto deben alejarse del pequeño centro urbano y buscar playas y otras áreas boscosas de zonas vecinas.

El destino es un componente fundamental de la empresa o actividad turística y Jacó, continúa siendo un lugar muy visitado tanto por nacionales como por extranjeros. Una vez allí surgen las preguntas: qué hay para ver, para hacer y para comer. Esta última interrogante será nuestro foco de interés, después de presentar algunos aspectos metodológicos.

\subsection{Registro del corpus}

El enfoque de este estudios es interdisciplinario, específicamente desde la antropología lingüística, pues observamos el comportamiento de los hablantes centrados "en la acción lingüística y en el discurso situado"
(Duranti, 2003:27) y lo analizamos desde una perspectiva lexicográfica y etnográfica. El corpus se cifra en la oferta gastronómica de Jacó, a partir de los nombres de los establecimientos dedicados a la venta de comidas y bebidas. El registro lo complementamos con la consulta de las guías de turismo local, panfletos y volantes (con la promoción de algún "combo" o producto nuevo), anuncios publicitarios (vallas en las carreteras, textos en periódicos y otros medios) y desplegables sobre un restaurant u otro establecimiento afín.

Para acercarnos al significado de estos lugares, registramos los rótulos donde se escribe el nombre del restaurant, cafetería, bar, soda, refresquería, para luego clasificarlos semánticamente. Esto requirió un trabajo de campo, que realizamos en el mes de setiembre ${ }^{2}$ del 2012, en la calle principal de Jacó. Recorrimos ambos lados de la calle principal, donde se ubican la mayoría de establecimientos comerciales y se anotaron los nombres, tal como estaban escritos en el rótulo o en la ventana. También, registramos los principales establecimientos esa calle y la playa. No incluimos los hoteles ${ }^{3}$, pues la mayoría son resorts o cabinas de lujo, ubicadas fuera del centro.

En algunos casos (según las posibilidades, condicionadas por el horario y la cantidad de clientes por atender) sostuvimos una breve conversación con la persona que administra o atiende el lugar y le preguntamos acerca del tipo de turista que llega a consumir ese lugar. Esta información la completamos con la observación directa.

FOTOGRAFÍA 1. Restaurant Red Lobster, en Playa Jacó

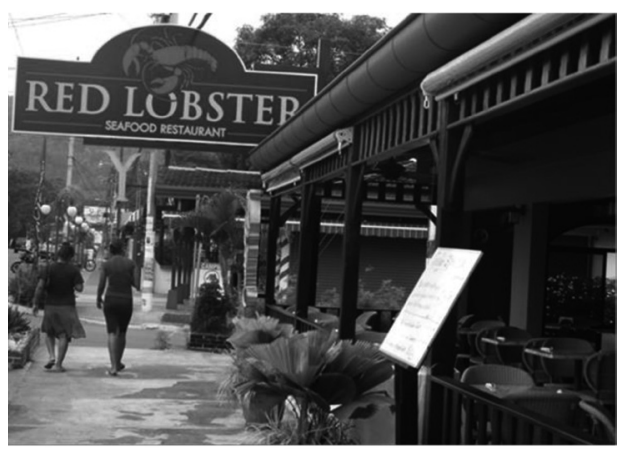

Foto tomada por Diana Díaz, setiembre, 2012 


\section{Clasificación de la oferta} gastronómica de Jacó

\subsection{Lengua o lenguas en que está escrito el nombre del lugar}

Este trabajo se limita a registrar los nombres de restaurantes, sodas, cafeterías, bares, refresquerías, heladerías y lugares afines donde se venden comidas y bebidas. Se excluyen los nombres de cabinas y hoteles, ya que el otorgamiento del nombre, se refiere exclusivamente a promocionar la oferta gastronómica.

TABLA 1.

Nombres de restaurantes y afines, según lengua. Jacó, 2012.

\begin{tabular}{ll}
\hline Lengua & Jacó \\
\hline Español & El pícaro, Parri pollos, Pa' picar, El Barco de los Mariscos, \\
(25) & Marisquería El Recreo, El hicaco, Jacobeña, La cevichera, \\
& El paso del tigre, Marea alta, Malecón, Mono verde, \\
& Poseidón, Pili Pili \\
& Heladería El Barco, Cosechas, Granizados Artesanales, \\
& Granizados La Veranera, \\
& Granizado Pingüino, Paladares, Soda Raquel, Soda Clarita, \\
& Soda EI Recreo, Soda Acachete (algo que está tuanis) \\
\hline Inglés & Taste buds, Beach Burger, Subway, KFC (Kentucky Fried \\
(20) & Chicken), Kenny's pub and grill, Red Lobster, TCBY \\
& (the country's best yogurt), Pops, Pachi's, Surf Dogs, \\
& Garden of Lions, Golden Garden, Monkey, Beatle Big Ron, \\
& Vegetarian, Lemon Zest, Pacific Bistro \\
& (Pizza) Big Bamboo, The Coffe Shop, Black Beards \\
\hline Italiano (4) & Peccati di Gola, Musmanni, Paparazzi, Lanterna \\
\hline Japonés (2) & Arigato, \\
& Tsunami sushi \\
\hline Otro (1) & Quiznos \\
\hline Bilngüe (2) & Gelateria il barco/Heladeria el Barco, \\
\hline Combinación de lenguas ${ }^{4}$ & The Wok/ La Olla (china) \\
\hline (10) & Le Loft, Amigo's Pizza Hut, Caliche's \\
& Parrillada Argentina Aberdeen- Angus, \\
& Taco Bar, Tarrazú Beach Café, Jaco Bell, Mono verde \\
\hline
\end{tabular}

Las lenguas más frecuentes son el español y el inglés, con una pequeña diferencia de cinco nombres. Pero, si excluimos los nombres de transnacionales estadounidenses (KFC, TBCY, Subway, Quiznos, Pizza Hut, Mandarina Tropical Juice), los nombres en inglés se reducen a catorce establecimientos sin franquicia, cuyos dueños prefirieron ese idioma que en la actualidad cumple un rol de lengua internacional, según las funciones que Fasold atribuye a las lenguas. (Moreno Fernández, 1998: 238). Casi una veintena de nombres están escritos en otros idiomas, pero al tomar en cuenta que el español es la lengua oficial del país, nos parece que la influencia de otras lenguas es considerable. 
Los datos muestran que no conoce o se irrespeta la ley $\mathrm{N}^{\circ} 7623$, "Defensa del idioma español y de las lenguas aborígenes costarricense" (del 11 de setiembre de 1996), que ha tenido mucha oposición de parte de los comerciantes por las multas contra quienes no acaten las normas:

Artículo $1^{\circ}$.- Escritura preceptiva. Deberán escribirse correctamente en español o en lenguas aborígenes de Costa Rica: .../...d) Los rótulos y anuncios, la publicidad, los lemas y emblemas de propaganda, las explicaciones impresas en instrucciones, envases, empaques o embalajes de productos, con el fin de informar a los consumidores. e) Los documentos públicos, las publicaciones y revistas de la Administración Pública. .../... g) Los folletos y afiches de información turística y los menús, sin perjuicio de que puedan publicarse o imprimirse, junto con su traducción, en otras lenguas.

Artículo $2^{\circ}$.- Traducción a un idioma extranjero Junto a los rótulos y anuncios, podrá colocarse su traducción a otro idioma, siempre que no se destaque sobre lo escrito en español.

En la tabla 1, observamos que solo se tradujeron los nombres de un restaurant (The Wok) y una heladería (Gelateria Il barco).

Además, no se respetan las normas prosódicas, ortográficas y gramaticales de la lengua española, que se exigen en el artículo 4 para documentos de la administración pública. $\mathrm{Si}$ bien, los rótulos con los nombres de restaurantes son privados, la escritura intencional con la mezcla de reglas sintácticas, cumple su objetivo de llamar la atención, aunque confunde a quienes lo leen (por ejemplo, Caliche's bar, en lugar del Bar de Caliche, es una fórmula muy usual en el país); otro ejemplo es el Mono verde Bistro, cuya sintaxis es inglesa, aunque el nombre del lugar sea en español y el tipo de establecimiento sea en francés (bistro o bistrot), para referirse a un lugar donde originalmente se vende vino y café, pero por ampliación semántica también se venden carnes y otros platillos.

\subsection{Lengua o lenguas en que está escrito el nombre de las comidas y bebidas en el menú}

Jacó es un ejemplo de contacto de lenguas y culturas, pues además de la población local, hay una gran cantidad de movimientos de personas, en su mayoría turistas nacionales y extranjeros. A esta se suma otro grupo numeroso, conformado por los llamados agentes de compañías comerciales, que son proveedoras de alimentos, transporte y otros elementos de la actividad turística. Por lo tanto, en la escritura del menú se utiliza el español, el inglés, el italiano y la mezcla o combinación de lenguas.

En Jacó predominan los menús en inglés, aunque también está la traducción al español (inglés-español e italiano-español), aunque esa no es la tendencia. En este caso, también se evidencia el incumplimiento a la Ley $\mathrm{N}^{\circ} 7623$, pues no siempre aparece el nombre de platillos y bebidas escritos en lengua española y es frecuente que se destaque el nombre en otra lengua y se minimiza el español.

FOTOGRAFÍA 2.

Menú en español, escrito en la pared de una soda de Jacó

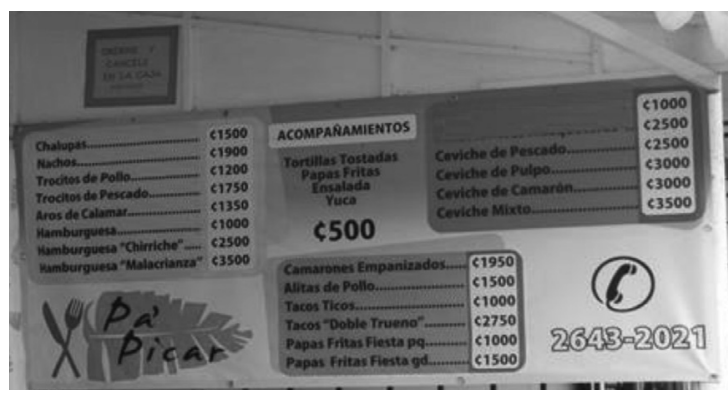

Foto tomada por Esteban Romero, setiembre 2012) 
Los nombres de los platillos son semejantes a los de otros restaurantes, bares, cafeterías o sodas de otros lugares del país. Es común encontrar en español algunos platillos como gallo pinto, casados, patacones, tortilla palmeada, sopas, ensalada de caracolitos. El menú escrito en inglés incluye entre sus comidas: Jamaican curry chicken, jamaican oxtail, sweet sour chicken , bbq pork, Cantonese rice and noodles, chicken dumplings, pan fried, fish snapper, Vietnamese spring rolls, and bamboo, rosted pork, chinese sausage, steak, shrimps, mix salad, dorado or mahi mahi, yellow fin tua, malay style beef rendag, green curry chicken, singapore pork ribs, Asian meat balls, ginger, peanut sauce, pan cakes, french toasts, entre otros.

La oferta italiana es muy variada, desde los entremeses, platos principales y postres: carpaccio, bruschetta, vitella tonnato, ensalada mixta parma y bresaola, pollo Ferrari, a la boscaiola, parmesano, al limón, lomito a la pimienta, filet ghiotto. La oferta de pastas comprende cortas (penne, rigattoni, fusilli, farfalle, etc.) y largas, además de gnocchi de papa y variedad de pizzas. En el menú de comidas italianas, más que una traducción, lo que hay es una descripción de los principales ingredientes o técnicas utilizados en la elaboración de un platillo.

La oferta asiática es variada pues incluye comida japonesa, china y tailandesa, como carnes en salsa teriyaki, sushi, tallarines con salsas de pescado, zacate de limón, jengibre, entre otras. El menú de comidas variadas comprende: pizza slice, subs, garlic rolls. La oferta mexicana comprende tacos, burritos, nachos, enchiladas, sopa azteca y la cocina estadounidense se asocia con hamburguesas y alitas de pollo con salsa barbacoa.

Las refresquerías ofrecen bebidas como: banana tropical, ice cream de variados sabores tropicales y foráneos, iced coffe, sundae, milk shakes, smoothies a base de frutas tropicales de diferentes sabores.

\subsection{Lugar de origen de las comidas y bebidas}

Jacó es un poblado que vive para el turismo. Aunque la mayor parte del turismo que visita la región del Pacífico Central procede de Estados Unidos, también hay visitantes de otros lugares y también nacionales, que gustan deleitarse con comidas variadas. Los restaurantes y otros establecimientos afines son de propiedad de costarricenses y de extranjeros. Aunque no los consideremos "gastronomía", si son comunes los lugares de comidas estadounidenses, tipo franquicia, con una oferta de comidas rápidas, conocidos internacionalmente (por ejemplo, K.F.C., Quiznos, Pizza Hut,), aunque su personal administrativo y logístico es costarricense, de la localidad.

TABLA 2

Origen de la oferta gastronómica de Jacó

\begin{tabular}{llll}
\hline $\begin{array}{l}\text { Origen de la oferta } \\
\text { gastronómica }\end{array}$ & $\begin{array}{l}\text { Nombre del restaurant, } \\
\text { café o afín }\end{array}$ & $\mathbf{N}^{\circ}$ & $\mathbf{\%}$ \\
\hline Comida Asiática & $\begin{array}{l}\text { Tsunami Sushi, Arigato, } \\
\text { The Wok/La olla china, } \\
\text { Restaurant y Bar Garden } \\
\text { of Lions, } \\
\text { Golden Garden, }\end{array}$ & & \\
& Taste Buds & & \\
\hline Comida caribeña & $\begin{array}{l}\text { Paladares, } \\
\text { Pili Pili }\end{array}$ & 1 & 1.6 \\
\hline Comida Fusión Caribe & 2 & 3,12 \\
Asia & $\begin{array}{l}\text { El Picaro, Le Loft, } \\
\text { Peccati di Gola, }\end{array}$ & 4.3 \\
\hline Comida Italiana & Lanterna & & \\
&
\end{tabular}




\begin{tabular}{|c|c|c|c|}
\hline Comida Mexicana & $\begin{array}{l}\text { Mexican Joe's, } \\
\text { Jaco Bell }\end{array}$ & 2 & 3.12 \\
\hline Comida Rápida & $\begin{array}{l}\text { Parri Pollos, Pa' picar, } \\
\text { Beach Burger, Pizza Hut, } \\
\text { Quiznos, Subway, KFC. }\end{array}$ & 7 & 10.9 \\
\hline $\begin{array}{l}\text { Comida ("Americana") } \\
\text { Estadounidense }\end{array}$ & $\begin{array}{l}\text { Kenny's pub and grill. } \\
\text { Lemon Zest }\end{array}$ & 2 & 3.12 \\
\hline $\begin{array}{l}\text { Variado e } \\
\text { Internacional }\end{array}$ & $\begin{array}{l}\text { Los Amigo's, Caliche's, } \\
\text { Big Ron's, } \\
\text { Beatle's Bar, Monkey's } \\
\text { Bar } \\
\text { The Coffee Shop, Pacific } \\
\text { Bistro } \\
\text { Lemon Zest, Black } \\
\text { Beards, Poseidón }\end{array}$ & 10 & 15.6 \\
\hline Comida nacional & $\begin{array}{l}\text { Soda Marea Alta } \\
\text { Soda Raquel } \\
\text { Clarita's Bar y Restaurant } \\
\text { El paso del tigre }\end{array}$ & 4 & 6.3 \\
\hline Comida vegetariana & Vegetarian Café & 1 & 1.6 \\
\hline Parrilladas & $\begin{array}{l}\text { Parrillada Argentina } \\
\text { Aberdeen- Angus } \\
\text { Mono verde Bistro }\end{array}$ & 2 & 3.12 \\
\hline Marisquería & $\begin{array}{l}\text { L'Esperanza, El Barco de } \\
\text { los Mariscos, Taco Bar, } \\
\text { Marisquería El Recreo, } \\
\text { Red lobster, El hicaco, } \\
\text { Jacobeña, } \\
\text { La cevichera, } \\
\text { Malecón Bar y Restaurant }\end{array}$ & 9 & 14.0 \\
\hline Soda & $\begin{array}{l}\text { Soda EI Recreo, Soda } \\
\text { Acachete }\end{array}$ & 2 & 3.12 \\
\hline Panaderías & Musmanni, Pachi's & 2 & 3.12 \\
\hline Cafeterías & Tarrazú beach café & 1 & 1.6 \\
\hline $\begin{array}{l}\text { Heladería, jugos y } \\
\text { batidos, granizados, }\end{array}$ & $\begin{array}{l}\text { TBCY, Pops, Surf Dogs, } \\
\text { Cosechas, } \\
\text { Heladería El Barco/ } \\
\text { Gelateria il Barco, } \\
\text { Mandarina Tropical } \\
\text { Juice Bar, Granizados } \\
\text { Artesanales, } \\
\text { Granizados La Veranera, } \\
\text { Granizado Pingüino }\end{array}$ & 9 & 14.0 \\
\hline \multirow[t]{2}{*}{ total } & & & 100 \\
\hline & & 54 & \\
\hline
\end{tabular}

En la tabla $\mathrm{N}^{\circ} 2$, observamos el predominio de la comida internacional, las marisquerías y heladerías. Esta oferta es congruente con el "pequeño mundo cosmopolita" que se halla en Jacó y su relación con un medio natural: el mar y los frutos marinos; el clima tropical que 
propicia el gusto por bebidas refrescantes como los helados y refrescos de frutas. Si agregamos las ventas ambulantes de granizados, en las playas y en las calles de la ciudad, este rubro es el más numeroso.

Podemos afirmar que hay congruencia con la oferta y el contexto natural, ya que las marisquerías y las refresquerías ocupan el segundo lugar, con un $14 \%$ de establecimientos en cada tipo de comercio. La mayoría de los restaurantes tiene patente para la venta de cerveza y licores, lo que tiene gran demanda tanto de día como en la noche. El tercer lugar corresponde a los lugares de venta de comidas rápidas, con un $10.9 \%$, cifra intermedia en la oferta total, que denota un asunto de gusto, mediatizado por la publicidad.

No aparece ningún lugar con una oferta de la cocina francesa, que es de las más famosas del mundo. Suponemos que esto se debe a que el turismo predominante es el estadounidense, ya que el europeo es más frecuente en otras zonas del país. Sin embargo, en Jacó hay unas pocas personas francesas, dedicadas al comercio en otras áreas.

\section{Clasificación semántica de los restaurantes $y$ afines}

El ordenamiento de los nombres de los establecimientos donde venden comidas y bebidas es una tarea que contribuye a estimar la relación del significado de esos nombres y el entorno natural y cultural. Para realizar esta clasificación, nos basamos grosso modo en la propuesta de Flor Garita (1995).

4.1- Nombres propios

4.1- Antropónimos:

4.1.1- Apellido: Musmanni

4.1.2- Nombres de pila: Carlota, Raquel,

4.1.3- Hipocorísticos: Caliche, Pili Pili, Pachi, Kenny, Ron

4.2- Procedente de Topónimos:

4.2.1- Topónimos Indígenas: Tarrazú

\subsection{2- Topónimos del área: Jacó}

\subsection{3- Foráneos: Kentucky}

El apellido es de origen italiano; los nombres de pila son femeninos; los hipocorísticos son masculinos, a excepción del diminutivo de Pilar (Pili duplicado). No hay ningún hagiotopónimo, que sí es frecuente en el Valle Central, lo que se explica por el tipo de poblado que es Jacó, donde la diversión es lo que impera y no tiene mucho sentido un nombre ligado a Dios, la Virgen María o los santos.

4.2- Nombres comunes:

\subsection{1- Componentes del ambiente}

4.2.1.1- Fauna: Pingüino, pollos, tigre, mariscos, monkey, lions lobster, dogs, buds,

4.2.1.1- Flora: frutos como el hicaco y la mandarina, flor como la veranera

4.2.1.3- Otros: agua, sol

4.2.1.4- Aporte humano al ambiente:

4.2.1.4.1- Artefactos o construcciones humanas: barco, bell, cosechas, garden, malecón, loft; taco, pizza, sushi, burger, bar, granizado, heladería, café, restaurante, soda cevichera, marisquería, parrillada

4.2.1.4.2- Actividades: surf, picar, taste.

4.2.1.4.3-Actitudes: esperanza,recreo.

4.2.1.4.4-Comportamientos: gola (gula), pecati (pecados),

4.2.1.5-Tipos humanos: Amigo, arigato, Beatle, jacobeña, pícaro

4.2.2-Características del accidente geográfico

4.2.2.1-Configuración: beach, malecón, tsunami 4.2.2.2-Cualidades:

4.2.2.2.1-Cromáticas: azul, red, golden, verde;

4.2.2.2.2-Tamaño: alta, big;

4.2.2.2.3-Movimiento: marea, amanecer.

4.2.2.2.4-Otras: acachete (algo que está tuanis), artesanales.

En los componentes del ambiente hay más frecuencia de nombres de animales, entre ellos algunos de la región (monkey (mono), tigre, lobster (langosta). En el aporte humano al ambiente, en los nombres de restaurantes y afines predominan las construcciones humanas, que guardan relación con el entorno de Jacó (por ejemplo: barco, malecón, marisquería). 


\section{Tipo de turista que consume en ese lugar}

Estos centros turísticos son visitados tanto por turistas nacionales como extranjeros, la mayoría estadounidenses. Jacó tiene una infraestructura hotelera moderna, cabinas, que son ocupadas por familias o grupos de amigos. Debido a la diversificación del turismo hay atractivos para personas de distintas edades, pero es común que las personas mayores consuman los alimentos en los resorts, como parte de un paquete, mientras que la gente más joven visita los lugares que mencionamos.

Los nacionales viene sobre todo en fin de semana o en temporada de vacaciones escolares y según dicen, proceden de distintas regiones del país, de donde llegan ya sea en automóvil, en autobús o en paseos organizados por los miembros de un barrio o poblado, quienes contratan una microbús.

Debido al costo de los servicios en la mayoría de centros turísticos, solo una minoría de costarricenses consumen en restaurantes locales, a excepción de algunas sodas. La opción más cómoda es llevar la comida preparada o ir a sodas ubicadas al costado de la carretera (que conduce a Quepos), pues en estos lugares un almuerzo promedio, tipo "casado" con arroz, frijoles, ensalada, picadillo de verduras, algún tipo de carne, plátanos maduros, tiene un costo de $\$ 5,00$ (2.500,00 colones), con el refresco y el impuesto incluido.

\section{El Lenguaje como instrumento publicitario}

Hay consenso entre los especialistas que los mensajes publicitarios en el campo del turismo deben ser verdaderamente persuasivos, de manera que, como apunta Dahdá (citado en (Almazán y Armenta, 1996:36), “alteren el funcionamiento psicológico del individuo, de modo tal que éste responda al objeto de la persuasión con formas de comportamiento deseadas o sugeridas por el persuasor".
Este puede ser un individuo o una entidad colectiva, intermediaria del turismo, que se vale de la palabra y otras imágenes (visuales, odoríferas) para lograr su misión, en este caso ir a comer a cierto lugar. Su discurso se realiza a través de una amplia gama de géneros textuales y en este artículo tomamos el mapa de la región Pacífico Central del ICT (Instituto Costarricense de Turismo) y el folleto con la guía turística Jacó Travel Guide.

Como lo señalamos en otro trabajo sobre las imágenes léxicas y visuales del turismo (Chang Vargas, 2010), la ideología está presente en todo discurso y la publicidad es uno de los medios para difundir valores de prestigio y de consumo. Es frecuente que, a pesar de los diferentes ámbitos territoriales y sociales, los textos publicitarios tengan un común denominador, sin importar el destino, al usar frases sugestivas que juegan el papel de instrumentos para atraer turistas. En el menú, rótulos o en folletos turísticos locales, como la Guía de Jacó, contribuyen frases como:

Jaco offers a wide selection of great food the best in town (sobre los smoothies o granizados),

a healthy fusion of asian fine cuisine,

The famous gallo pinto

We have the best lobsters dishes

The most popular choices in Jach

Visit the world famous Taco Bar

The most unique and memorable Costa Rican experience

A great selection of cocktails, wines and fusion cuisine

in a slick and sophisticated atmosphere

En negrita marcamos las palabras que cumplen el papel de ser un instrumento-gancho para que los turistas consuman en un lugar determinado. En toda Costa Rica venden gallo pinto para el desayuno, pero en cierto lugar de Jacó se halla ese famoso platillo típico. Observamos el uso de adjetivos (wide, great, healthy, famous) y de superlativos (the best, most popular). No faltaba complacer a visitantes con gustos variados y por eso la oferta de la cocina fusión, que compite con la típica $\mathrm{y}$, a ambas los intermediarios las califican de auténticas, 
palabra clave en la demanda y que la oferta debe lograr.

\section{Conclusiones}

El ideario del turista que busca el refugio en la naturaleza es algo del Jacó de ayer, del otrora pueblo de pescadores de antes del último tercio del siglo XX. El Jacó de hoy, ya sea que lo miremos desde lejos (por la carretera, donde se divisa la ensenada que antes estaba cubierta de palmeras, hoy vemos una "siembra" de edificaciones y yates) o cerca (la calle principal, llena de gente que visita negocios de comida, souvenirs y otros), se parece más a un mini-Miami. No obstante, en vez de español, la gente prefiere el inglés. Si se busca la comida, la oferta gastronómica no se queda atrás de los grandes balnearios, pues allí el turista encontrará la auténtica cocina postmoderna, pues la calle central es un caleidoscopio de comidas de diferentes orígenes, donde lo nacional es minoritario, excepto si se trata de marisquerías. Irónicamente, se puede sentir como en casa, es decir, como en la mayoría de las ciudades (excepto las bolivianas), pues hay varias opciones de fast food, para complacer el gusto infantil y juvenil.

El idioma que prevalece en los rótulos es el español, pero lo siguen muy de cerca, la onomástica de restaurantes escrita en inglés, a pesar de la ausencia de una Comisión Cantonal que vigile por el cumplimiento de la Ley $\mathrm{N}^{\circ}$ 7623. Esto denota la falta de interés municipal, pues en caso de inopia de lingüistas, la ley permite que un profesor de español asuma el rol de defensor del buen uso del idioma.

En Jacó, ¡todo se vale! Y por eso son frecuentes los rótulos que combinan palabras de diferentes idiomas, pues puede resultar exótico para los visitantes nacionales y extranjeros. En relación con la semántica de los nombres no es mucha la relación entre el nombre y su relación con el medio, excepto en algunos como malecón, marea alta, marisquería, monkey, beach, jacobeña e hicaco.
No hay correspondencia entre la oferta gastronómica y el interés por reforzar la identidad regional o revitalizar las comidas de valor como herencia o patrimonio cultural regionalo nacional. El mensaje que transmiten por medio de los nombres de restaurantes, de platillos o bebidas comunica la penetración foránea en el lenguaje, el abandono de lo propio y una tendencia al olvido de la cocina local. Este pequeño trabajo es una muestra de la estrecha relación que existe entre lengua, sus usos y el cambio sociocultural.

El lenguaje del turismo recurre a los préstamos lingüísticos como estrategia para captar mayor clientela, pues predominan los anglicismos. Si confrontamos la relación entre las actitudes sociolingüísticas y los usos lingüísticos, en el caso estudiado, podemos afirmar que sí hay concordancia o convergencia de intereses comunicativos, pues la mayoría de turistas proceden de Estados Unidos. Si a este hecho tangible, agregamos uno intangible, como la penetración ideológica, pues el resultado es la aceptación de imágenes gramaticales y léxicas, con elementos icónicos que remiten a una lengua y cultura foráneas.

Corroboramos que el turismo es ambivalente, complejo y contradictorio en una diversidad de campos y el gastronómico es uno de ellos.

\section{Bibliografía}

Almazán, Blanca Estela y Ruth María Armenta. (1996). Identidad e imagen turística. México: Universidad Autónoma del Estado de México.

Asamblea Legislativa. Ley $\mathrm{N}^{\circ} 7623$, “Defensa del idioma español y de las lenguas aborígenes costarricense". San José, Costa Rica.

Burns, Peter M. (2005). Turismo e Antropología. Uma introdução. Brasil, Edit. Chronos. 
Calvi, Maria Vittoria. (2010). "Los géneros discursivos en la lengua del turismo: una propuesta de clasificación". En: Ibérica 19 (2010): 9-32. http://www.aelfe.org/ documents/01_19_Calvi.pdf Consultada el 24 de mayo, 2012.

Calvi, M.V. (2007). "Ricerca lingüistica e turismo". A cura di C.di Stasio e O. Palusci. The Languages of Tourism. Turismo e Mediazione. Milano: Edizione Unicopli. pp. 203-208.

Canestrini, D. (2001). Trofei di viaggio. Per un' antropologia del souvenir. Torino. Bollati Boringhieri.

Cordero, A. y L. Van Duynen Montijn. (2002). "Turismo sostenible en Costa Rica? El caso de Quepos, Manuel Antonio", En : Cuaderno de Ciencias Sociales 123, San José, Costa Rica: FLACSO. pp. 43-65

Chang Vargas, G. (2011). "Imágenes léxicas y visuales en las prácticas discursivas del turismo ambiental y cultural de Costa Rica”. En: Altre Modernità. Confini Mobile: lingua e cultura nel discorso del turismo. Università degli Studi di Milano. Facoltà di Lettere e Filosofia. Sezione di Studi Culturale. pp. 88-104. 2/12http://riviste.unimit.it/index/php/ Monline/article/view/1977/2227

Chang Vargas, Giselle. (2000). Nuestras Comidas. Libro $\mathrm{N}^{\circ} 3$, Serie Culturas Populares Centroamericanas. San José, Costa Rica: Coordinadora Educativa y Cultural Centroamericana (CECC).

Dann, G. (1996). The Language of Tourism. A Sociolinguistic Perspective, . USA: CAB International.
Duranti, Alessandro. (2000). Antropología Lingüística. Madrid: Cambridge University Press.

Garita Hernández, Flor. (1995). Toponimia de la provincia de Cartago. San José : MCJDEditorial UCR-Comisión Nacional de Nomenclatura.

Gumperz, John and Dell Hymes (Eds.). (1972). "Introduction. Toward ethnographies of Communication", En: Directions in Sociolinguistics: The Ethnography of Communication, New York \& London: Holt, Rinehart and Winston.

Hein, W. (2002). "Postfordismo y desarrollo regional sostenible con base en el turismo: visión de conjunto de resutados." En: Fürst, Edgar y Wolfgang Hein (editores). 2002. Turismo de Larga Distancia y desarrollo Regional en Costa Rica. Costa Rica y Hamburgo: DEI y DUI

Hiernaux Nicolas, Daniel. (2002). “Turismo e imaginarios". En: Imaginarios y turismo sostenible. Cuaderno de Ciencias Sociales 123, San José, Costa Rica: FLACSO. pp.7-34.

Instituto Costarricense de Turismo. (2009). Mapa de la Zona Turística Pacífico Central. San José: Costa Rica.

López Guzmán, Tomás y Sánchez Cañizares, Sandra. (2012). "La gastronomía como motivación para viajar. Un estudio sobre el turismo culinario en Córdoba". En PASOS 10 (5), pp.575-584.

Moreno Fernández, Francisco. (1998). Principios de sociolingüística y sociología del lenguaje. Barcelona: Ariel. 
Rosero Bixby, Luis. (2002). Estimaciones y proyecciones de población por distrito y otras áreas geográficas. San José: Centro Centroamericano de Población UCRINEC. http://ccp.ucr.ac.cr/bvp/pdf/proye/ distrital.pdf.
Ross González, Marjorie. (2001). Entre el comal y la olla. Fundamentos de gastronomía costarricense. San José: EUNED.

\section{(c) (1) (9)}


